\title{
LA DISCRIMINACIÓN INVERSA Y EL CASO KALANKE*
}

a sentencia del Tribunal de Justicia de las Comunidades Europeas de 17 de octubre de 1995, sobre el llamado caso Kalanke (un ingeniero que competía con una ingeniera, llamada Glissmann, por la jefatura de sección del Servicio de Parques y Jardines de la ciudad de Bremen), ha considerado contraria a una Directiva de la Comunidad una norma del Land alemán de Bremen de 1990 que en los ascensos en la función pública concedía

«preferencia a las mujeres frente a los candidatos masculinos con la misma capacitación si, en el sector de que se trata, están infrarrepresentadas».

Así se ha vuelto a poner de actualidad la cuestión de la legitimidad de la discriminación inversa o positiva y su relación con las medidas de acción positiva. Las páginas que siguen pretenden fundamentalmente dos cosas: plantear las relaciones entre acciones positivas, discriminación inversa y discriminación clásica para proponer algunas consideraciones justificatorias de la discriminación inversa y formular una crítica de la sentencia del Tribunal de Luxemburgo y de los criterios que la fundamentan. Antes de todo ello, sin embargo, avanzaré unos comentarios generales que servirán también como declaración expresa de mis criterios o, si se prefiere, de mis prejuicios.

\section{Un punto de partida igualitario}

Una de las críticas que ha recibido la sentencia del caso Kalanke, es que ninguno de los once jueces que la dictó era mujer (y lo mismo se aplicaría,

* El presente texto -que se integra en el proyecto de investigación núm. PB94-0193, del Programa Sectorial de Promoción del Conocimiento de la DGICYT- amplía considerablemente mi contribución a una mesa redonda organizada por la Fundación Mujeres el 6 de noviembre de 1995, cuya primera elaboración se publicó, como «Discriminación inversa, acciones positivas e igualdad (a propósito de la sentencia del caso Kalanke)», en la revista Jóvenas (nn. 4-5, 1995, pp. 98-108); como no recibí pruebas de esa primera versión, en ésta he introducido algunas correcciones que habrían debido aparecer ya en aquella publicación.

Agradezco a mis compañeros del Área de Filosofía del Derecho de la Universidad Autónoma de Madrid las varias y valiosas observaciones que hicieron en la sesión del seminario dedicada a la versión anterior de este texto. 
hoy, al Tribunal Constitucional español o a la Corte Costituzionale italiana, que no hace mucho tiempo rechazó la constitucionalidad de la legislación electoral que establecía ciertas medidas de discriminación inversa en favor de una mayor igualdad en las candidaturas municipales entre hombres y mujeres ${ }^{1}$ ).

Alguien podría pensar que, por ello, la intervención de un varón en este tipo de debates no hace más que echar leña al mismo fuego. Creo, sin embargo, que asumir culpas colectivas por los comportamientos de otros especímenes del propio grupo sería contradecir los presupuestos morales básicos desde los que parece exigible la igualdad entre hombres y mujeres y, por ella misma, las propias políticas de discriminación inversa. Y por la misma razón, que sea un varón quien adopte y argumente en favor de ese punto de vista -de modo simétrico a como también hay mujeres que se oponen a él- podrá ser difícil de explicar para quien crea en la desigualdad básica entre hombres y mujeres, pero no para quien mantiene justamente el punto de vista opuesto.

Las alianzas cruzadas suelen ser aquí complejas, pues si las mujeres que se oponen a la discriminación inversa suelen hacerlo predominantemente en nombre de la igualdad entre los sexos, en el caso de los hombres esa misma oposición tiende a cubrirse bajo el manto de la diferencia y su lema «diferentes pero iguales». Pero la idea de diferencia, que algunas mujeres también pueden tener la tentación de alegar como razón de la discriminación inversa, es peligrosa compañera que, al no apelar a la igualdad, fácilmente puede terminar desvelando el rostro de la peor desigualdad.

Con todo, como decía, la reproducción de alianzas complejas y cruzadas entre hombres y mujeres en favor o en contra de la discriminación inversa resulta bien natural y sencilla de justificar para quien, como el que suscribe, cree en la igualdad básica, no sólo ético-política sino también cognitiva, entre hombres y mujeres; o, por decirlo de manera algo más precisa, para quien considera que entre las múltiples diferencias entre hombres y mujeres, tomados todos y cada uno como individuos, ninguna les escinde como grupos incomunicables, radicalmente diferentes y, por tanto, fácilmente destinados a ser desiguales. Porque la igualdad deseable impone que, aceptando una gran diversidad de diferencias individuales, ninguna de ellas se adscriba a este o aquel grupo para aplicarlas después indiferenciadamente a los individuos que lo componen. Y para conseguir ese ideal es por lo

${ }^{1}$ Se trata de la sentencia 6-12 de septiembre de 1995, n. 422.

Sobre la legislación anulada por esta sentencia, críticamente, vid. Giuditta Brunelli, «L’alterazione del concetto di rappresentanza politica: leggi elettorali e «quote» riservate alle donne», Diritto e società, n. 3, 1994, pp. 545ss.; y «Azioni positive in materia elettorale?», Ragion Pratica, n. 4, 1995, pp. 243-50; escritos de los que la Corte Costituzionale italiana parece haber recibido amplia inspiración: cf. Maria Vittoria Ballestrero, «"Goals are good but quotas are bad". Discutendo di azioni positive e di quote», Ragion pratica, n. 5, 1996, p. 260, nota 3; este escrito de Ballestrero, en cambio, es crítico con la sentencia. 
que las medidas de discriminación inversa pueden ser, instrumental y temporalmente, defendibles.

\section{Acciones positivas, discriminación inversa y discriminación clásica}

\section{Discriminación inversa y acciones positivas}

La discriminación inversa, al parecer, nació en la India, ya en los años 30, como una política aceptada por los colonizadores británicos para intentar superar la aguda división en castas de aquella sociedad. Su conocimiento y extensión actual, sin embargo, procede de su introducción en los Estados Unidos a partir de principios de los años 70. En Europa, su formulación más conocida es la de las cuotas en órganos de partidos políticos, que se aplican en los países nórdicos desde principios de los años 80 y en España desde $1988^{2}$.

Dos casos que llegaron al Tribunal Supremo de Estados Unidos expresan bien los rasgos más salientes de la discriminación inversa. Por una parte, el caso Bakke, un estudiante blanco que había sido rechazado por una Facultad de Medicina que había reservado 16 de las 100 plazas de nuevo ingreso para minorías raciales desfavorecidas. Por otra parte, el caso DeFunis, otro blanco (aunque perteneciente a la minoría judía, sobradamente representada en el nivel universitario) que fue rechazado por una Facultad de Derecho que otorgaba puntos extra al mismo tipo de minorías. El primer caso, aunque no el segundo, fue declarado inconstitucional por el Tribunal Supremo, debido a la importancia que se atribuyó a la rigidez del sistema de cuotas frente al de puntos extra.

Sea como sea, lo cierto es que la pretensión de las políticas de discriminación inversa es intentar paliar situaciones de desigualdad particularmente recalcitrantes. La gravedad de tales situaciones explica la gravedad de la discriminación inversa, que tiene posibilidades de aplicación muy extremas, sobre todo en cuanto en la esfera laboral y universitaria parece prescindir de la idea de mérito, y todo ello explica también el que se trate de una figura jurídica y moralmente muy discutida.

Esa controvertibilidad, sin embargo, no tiene por qué afectar en igual medida a otro tipo de políticas de igualación social, dentro de las que la discriminación inversa se puede integrar como una forma particularmente severa pero sin ser identificada por completo con ellas. Me refiero a las llamadas

2 En el ámbito anglosajón existe una extenuante literatura sobre la discriminación inversa, una selección de la cual puede verse en mi artículo «Discriminación inversa e igualdad», en Amelia Valcárcel (comp.), El concepto de igualdad, Madrid, Fundación Pablo Iglesias, 1994, pp. 90-3. Desde un punto de vista jurídico-constitucional, trata el tema con amplitud, documentación y rigor Fernando Rey Martínez, El derecho fundamental a no ser discriminado por razón de sexo, Madrid, McGraw-Hill, 1995, pp. 83ss. 
acciones positivas, que pueden caracterizarse en general como todo tipo de medidas que tienen el fin de conseguir una mayor igualdad social sustantiva entre grupos sociales con problemas de discriminación o de desigualdad de oportunidades: valgan como ejemplos de tales acciones positivas las subvenciones para la contratación laboral de jóvenes o de mayores, las becas de enseñanza para familias de escasos recursos, las políticas de integración social de los gitanos o las ayudas para la contratación de minusválidos; o, en relación con la igualdad de las mujeres, las ayudas para guardería, las campañas de publicidad para la igualdad sexual, el fomento de cursos especiales de especialización y promoción para mujeres o la facilitación de trabajos a tiempo parcial y con horarios flexibles.

Dos requisitos fundamentales pueden servir para diferenciar la discriminación inversa del resto de las medidas de acción positiva: la atribución de una preferencia por determinados rasgos y la existencia de una particular escasez de recursos.

Ante todo, en efecto, la discriminación inversa favorece a una persona por su pertenencia a un grupo históricamente discriminado, preferencia que supone, de un lado, desigualdad y, de otro, utilización de un rasgo o motivo sospechoso. Téngase en cuenta que tal desigualdad no siempre es necesaria ni siquiera para llevar a cabo determinadas acciones positivas: así, las ayudas a guardería, que dadas las circunstancias sociales tienden a favorecer la incorporación al trabajo de las mujeres, pueden cumplir también esa función cuando se otorgan a cualquiera de los padres (no obstante, como en seguida diré, una ayuda de guardería sólo para la madre no es todavía, por sí sola, discriminación inversa). Por su parte, la utilización de un rasgo o motivo sospechoso es lo que permite hablar de «discriminación» en el sentido fuerte de la palabra, por el que la discriminación racial o sexual nos parece cualitativamente más grave que otras desigualdades, incluso injustas, como, por ejemplo, las que pueden afectar a las rentas de distintas regiones del mismo país: la relevancia de los rasgos sospechosos, como los enumerados en el art. 14 de nuestra Constitución, procede de la larga historia de gravísimas desigualdades que de forma opresiva y persistente han afectado a ciertos grupos caracterizados usualmente por la posesión de rasgos físicos -como el color o el sexo- o cuasi-físicos -los apellidos de los judíos, la adscripción a una religión, etc.-, que tienden a tener un carácter social transparente y son inmodificables o muy difícilmente modificables para los individuos que los portan y, final y decisivamente, cuya posesión ha sido tradicionalmente vista de forma socialmente negativa al menos por los grupos dominantes, sea sólo minusvaloradora o sea también despectiva y hasta estigmatizadora (como después diré, sin embargo, esto no quiere decir que toda medida que utilice un rasgo sospechoso sea necesariamente y siempre injusta).

Junto a la anterior, la otra condición necesaria de la discriminación inversa que la distingue de otras acciones positivas más moderadas y menos conflictivas es su localización en posiciones de particular escasez y, por tanto, 
de fuerte competitividad, como son los puestos de trabajo, las labores de responsabilidad laboral, los cargos políticos o las plazas universitarias, espacios en los que se compite, por decirlo así, cuerpo a cuerpo, en forma individualizada. Es verdad que ésta no es una condición tajante, de todo o nada, que permita distinguir netamente en los casos fronterizos, pero sí sirve al menos para excluir como formas de discriminación inversa muchas acciones positivas, en las que el coste de la medida tiende a repartirse difusa e innominadamente, por lo general sólo a través de impuestos. Así, no constituyen discriminación inversa, y no suelen plantear la oposición y conflictividad que ésta genera, las simples ayudas de guardería reservadas a las madres, las ayudas especiales a mujeres para cursos de especialización o perfeccionamiento, o los estudios sociológicos y las campañas publicitarias dirigidos a destacar la situación laboral femenina y otras similares ${ }^{3}$. Frente a ello, me parece menos relevante que, tratándose de puestos especialmente codiciados, la discriminación inversa se instrumente mediante cuotas, o con puntos extra o a través de objetivos como las llamadas «metas y calendarios», pues aunque las cuotas sean ciertamente la forma más extrema y llamativa de reservar plazas, también en las otras versiones se termina produciendo, aun determinada a posteriori, una reserva en condiciones de especial escasez que favorece a tal individuo frente a tal otro ${ }^{4}$.

Además de su importancia teórica, especialmente clarificadora, las anteriores distinciones tienen también relevancia práctica. Por un lado, si la discriminación inversa se justifica, con mayor razón se justificarán las medidas de acción positiva, que son menos «discriminatorias», costosas y socialmente conflictivas. Y, por otro lado, aunque la discriminación inversa no se justificara, eso no excluiría la justificación de otras medidas menos fuertes de acción positiva. En adelante defenderé que, al menos ciertas medidas de discriminación inversa, se pueden justificar, tanto ética como jurídicamente.

\section{De la discriminación clásica a la discriminación inversa}

$\mathrm{Al}$ oír la expresión «discriminación inversa» o «discriminación positiva», seguramente la tentación inmediata es resolver verbalmente el problema de su justificación, como, según se verá, hace en buena parte la sentencia

3 Para más datos, véase la enumeración de acciones positivas propuesta en la Recomendación del Consejo de Ministros de la CEE de 13 de diciembre de 1984 (84/635/CEE).

${ }^{4}$ En el caso de regulaciones como la del caso Kalanke, por lo demás, la diferencia práctica se evapora por completo, puesto que, a igualdad de méritos, el resultado de reservar una plaza a la mujer en igualdad de méritos cuando compite con un hombre es exactamente el mismo que el de atribuir a la circunstancia de ser mujer cualquier punto extra, por mínimo que resulte porcentualmente. En tal sentido, no concuerdo con la distinción con la que Atienza concluye «Un comentario al caso Kalanke», Cuadernos Jurídicos. Revista Mensual de Derecho, n. 39, marzo 1996, p. 12. 
de Luxemburgo. Probablemente, la idea que primero viene a la cabeza en este asunto viene a rezar más o menos así:

«¿Pero cómo van a ser justas las cuotas si son una discriminación, si violan el derecho de los hombres a ser tratados igualmente? la misma palabra lo está diciendo: discriminación inversa, o positiva, pero dis-cri-mi-na-ción a fin de cuentas y, por tanto, injusta; el fin no justifica los medios y la igualdad entre hombres y mujeres no puede conseguirse mediante discriminaciones».

Este tipo de respuestas se acoge de manera directa a la carga valorativa desfavorable del término «discriminación» ${ }^{5}$, que procede y se explica por siglos de opresión y desigualdad en contra de determinados grupos concretos pero que ha adquirido un significado abstracto y tiende a mirar a los dos lados de la relación: no se refiere ya sólo a los grupos tradicionalmente, y en parte todavía, discriminados, como los negros, los gitanos, los judíos o las mujeres, sino que, formulado en referencia genérica a la raza, la religión o el sexo, comprende también a los blancos, los payos, los gentiles y los varones, por donde cualquier distinción en favor de los grupos antes discriminados es discriminación en contra de los otros grupos. Y no es que esta abstracción carezca de toda justificación, conviene precisar, pues si mala fue la discriminación contra unos grupos en el pasado, eso no justificaría la revancha y siempre será conveniente prevenir similares injusticias en el futuro.

Con todo, el uso anterior del término «discriminación», claramente valorativo, comporta una absoluta identificación entre discriminación y distinción (o desigualdad) injusta que conviene analizar despacio. Evidentemente, en la lucha por elnombrar -que, recuérdese a Alicia, tiene mucho que ver con la lucha por el poder- el camino más fácil es aprovechar la carga peyorativa de aquel término y dar por zanjada la discusión. Y quienes primero nombraron en esta materia fueron, al parecer, quienes se oponían a la «discriminación inversa». La denominación, como ha ocurrido tantas veces en la historia, ha terminado siendo aceptada por quienes la defienden, sin que la alternativa de «discriminación positiva» mejore mucho las cosas: en el fondo, el problema está en el sustantivo «discriminación» y en su carga peyorativa y no en el adjetivo que lo califica. Por eso, para responder a quienes sostienen que tratar de eliminar la discriminación tradicional mediante otra es como intentar curar a un alcohólico a base de whisky, no basta con replicar que la segunda discriminación es inversa porque trata de devolver a sus justos términos lo que se había pasado de largo, o que es positiva porque tiende a promover la igualdad. Hay que decir eso, desde luego, y también que, como metáforas hay para todo, tales medidas pueden servir como

5 Es lo que hace José Luis Abellán, en «Sobre la discriminación positiva», El País, miércoles 1 de mayo de 1996, p. 29, donde afirma que «decir discriminación es lo mismo que decir irracionalidad», si bien se limita a «impugnar la discriminación positiva, no para negarla en toda su radicalidad, sino para reducirla al mínimo posible», usándola «con máxima prudencia» y reduciendo su aplicación «a muy contados casos», para «situaciones límite en que se hubieran agotado todas las posibilidades de una elección racional». 
el antídoto que neutraliza otro veneno o, mejor, como el clavo que saca otro clavo. Pero hay que decir más, pues el problema central está en el significado de las prácticas de discriminación, más allá del significado habitual, peyorativo, de la palabra «discriminación».

Por ello, tomemos por un momento el término «discriminación» en un significado puramente descriptivo o neutro, como cuando decimos que una persona distingue o discrimina bien entre conceptos diferentes. Pues bien, si discriminar en contextos normativos es distinguir sin más, aun tomando como base rasgos sospechosos como los de raza, sexo, religión, opinión política y similares, existen casos de discriminación, por muy excepcionales que puedan resultar, en los que no hay injusticia ninguna, sino todo lo contrario, que están perfectamente justificados, hasta el punto de que ninguna legislación los prohíbe: piénsese en la protección jurídica por parto, en posibles campañas sanitarias por enfermedades ligadas a los sexos, como el cáncer de mama o el de próstata, en la aceptabilidad de la contratación de personal de la propia religión o filiación política para tareas de administración y similares de la Iglesia o partido, o, aunque anecdótico pero expresivo, en la selección exclusiva de actores de una determinada raza para hacer una película histórica; en fin, en España el Real Decreto 1451/1983 obliga a las empresas con más de 50 trabajadores a reservar una cuota del dos por ciento de su plantilla para minusválidos y ningún tribunal ha considerado ilegal o inconstitucional tal reglamento. Y si hay casos de discriminación genérica (en el sentido descriptivo del término «discriminación») que, como los anteriores, parecen justificados, no hay que excluir que la discriminación inversa pueda también situarse entre ellos.

¿Por qué ha sido injusta la discriminación clásica contra los negros, los judíos o las mujeres? Pueden describirse cuatro rasgos típicos de la discriminación injusta, cuya gravedad explica por qué con sólo decir «discriminación» se suele implicar que se trata de distinción injusta:

$1^{\circ}$ ) una motivación social minusvaloradora, despectiva o, incluso, estigmatizadora: las personas contra las que se discrimina, caracterizadas por lo general mediante su pertenencia a un grupo socialmente señalado, son vistas, como mínimo, como inferiores en la medida en que, sea por razones físicas, intelectuales o morales, se las considera incapaces para realizar las tareas socialmente más importantes, de la administración de sus bienes a los cargos políticos o de responsabilidad laboral; y así como la negativa al sacerdocio de las mujeres da cuenta de la ideología que anima al conglomerado de provectos solteros que gobierna a la Iglesia católica, la preferencia laboral por los varones ante las cargas familiares de las mujeres, por más que pueda presentarse externamente como meramente utilitaria o económica por parte del empresario, depende a fin de cuentas de la existencia de un criterio social minusvalorador de la mujer, como residuo de una larga historia que la relega a la esfera privada, que es a fin de cuentas la no importante; 
$2^{\circ}$ ) una finalidad de desigualdad injusta, que mediante las acciones discriminatorias tiende a mantener y a perpetuar la inferioridad de las personas y el grupo desfavorecido: aunque en los casos más extremos, como el de la esclavitud de los negros o el de la persecución de los judíos, la discriminación ha podido conducir al genocidio o, al menos, a la explotación y a la opresión social, política y económica, tampoco en casos más moderados, como en el de la mujer occidental actual, dejan de aparecer formas bien conocidas de la desigualdad injusta, como su mayor índice de paro, su menor salario en promedio, su predominante acceso a los puestos laborales menos prestigiosos y pagados o, en fin, su inexistencia o invisibilidad en los puestos de responsabilidad de mayor prestigio. Para la mujer se verifica así el proverbio chino: «Los asuntos de las mujeres, por importantes que sean, son pequeños. Los asuntos de los hombres, por pequeños que sean, son importantes».

$3^{\circ}$ ) un objeto o contenido que afecta, además de a otros bienes, a la negación o la restricción de derechos básicos: en sus formas más extremas, el medio discriminatorio es jurídico, y en el caso de las mujeres no está tan lejana su exclusión del derecho al voto o al acceso a cargos públicos ni, hasta el final del franquismo, su incapacidad de plena disposición sobre su propia persona y bienes frente al marido; pero es importante advertir que la superación de este tipo de negaciones jurídicas no suele tener efectos taumatúrgicos en la esfera social, como lo prueba de manera clamorosa la situación de marginalidad social en la que se encuentra la minoría negra estadounidense: del reconocimiento de la igualdad formal por el Derecho a la realización de la igualdad real por la sociedad puede haber un largo trecho.

$4^{\circ}$ ) un resultado o efectos sociales que tienden a mantener, consolidar y perpetuar la situación de subordinación, marginación u opresión del grupo discriminado respecto del grupo que ejerce la discriminación; en algunos casos, por lo demás, los resultados discriminatorios pueden producirse como consecuencia de desigualdades fundamentadas en criterios y medidas de protección que operan de hecho afianzando la desigualdad preexistente: así, es conocido el mecanismo por el que ciertas medidas protectoras de las mujeres en la esfera laboral (exclusión de ciertos trabajos duros, pago especial de horas nocturnas, vacaciones especiales, etc.) tienen el efecto perverso de encarecer el trabajo femenino, desincentivando la contratación de mujeres y consolidando su desigualdad en esa esfera respecto de los hombres.

En contraste con los tres elementos anteriores, la discriminación inversa, en primer lugar, no contiene en absoluto ninguna motivación social despectiva o minusvaloradora ni que se pueda asemejar a ello ni siquiera de lejos: en el caso considerado por el Tribunal de Luxemburgo, el Land de Bremen no le dijo ni le dio a entender al Sr. Kalanke que prefería a su competidora porque él era inferior por pertenecer al minusvalorado o despreciado grupo de los varones, sino porque las mujeres están infrarrepresentadas en su sector laboral y, en igualdad de méritos, la ley le daba especial prioridad al logro de un objetivo de mayor igualdad social. En segundo lugar, la finalidad de la discriminación inversa es, y debe ser, efectivamente, conseguir 
una situación social más igualitaria entre grupos injustamente discriminados con anterioridad. $\mathrm{Y}$, en fin, el objeto de la discriminación inversa no afecta nunca a los derechos básicos que, como el voto, la libertad ideológica y de reunión o los derechos de defensa en juicio, no son sometibles a balances con fines sociales genéricos, sino sólo a la distribución de derechos o bienes sociales en los que, en diferentes contextos, se aceptan restricciones legales por finalidades de interés social, como en el caso del fomento a la contratación de trabajadores jóvenes, o mayores de cierta edad, etc.; naturalmente, si alguien replicara que la discriminación inversa afecta al derecho básico a la igualdad ante la ley, la respuesta debería ser, simplemente, que está concluyendo sin argumentos justamente aquello que se trata de demostrar, eso que los filósofos denominan petición de principio.

¿Quiere lo anterior decir que la discriminación inversa es por completo justa, necesaria y saludable, e inofensiva, aproblemática y generalizable? Yo no creo, ni me parece que sus defensores crean, que la discriminación inversa es la panacea que eliminará las desigualdades del mundo. Entre otras razones, porque puede aplicarse a cierto tipo de desigualdades y no a otras: así, es obvio que su utilización para cubrir los puestos sociales de responsabilidad o más prestigiosos no afecta a la desigualdad en los distintos puestos sociales mismos, sino sólo a que su distribución no esté desigualmente sesgada contra determinadas razas o contra las mujeres, como insistiré después con mayor detalle.

Por lo demás, hasta ahora no he considerado el argumento de que la discriminación inversa prescinde del criterio de los méritos, que es asunto sensible en sociedades ideológicamente meritocráticas como las occidentales. Aunque la apelación al mérito no se plantee propiamente en el caso considerado por la sentencia del tribunal de Luxemburgo -como tampoco se plantea, por cierto, en las cuotas en órganos de partidos políticos, al menos en la medida en que se piense que ahí se trata de elegir entre iguales y no de seleccionar por competencias académicas o profesionales-, la réplica estándar de que la discriminación inversa tiende a compensar los persistentes sesgos sexistas en la valoración de los méritos de las mujeres vale más en abstracto que en concreto. Quiero decir, vale más globalmente considerada, estadísticamente o en promedio, que a la hora de decidir en concreto qué hacer con esta reclamación en la que la reserva predomina sobre los méritos acreditados por quien juzga, donde el procedimiento de valoración de los méritos no viene impugnado por sesgar sus criterios discriminatoriamente contra la mujer. No digo que no haya también otras posibles razones mitigadoras de la seguramente excesiva preponderancia que se atribuye a los méritos individuales (en realidad, a cierta concepción sobre lo que son tales méritos) en la ocupación de puestos de responsabilidad, en los que por lo demás nadie pretende prescindir de las cualificaciones básicas necesarias. Pero el criterio de los méritos, entendido como selección de la persona que acredita ser la más cualificada en cada caso, presenta un patente conflicto 
con algunas formas de discriminación inversa y eso es una razón genérica para no considerar a ésta como una medida legal o moralmente obligatoria, a modo de razón excluyente de cualquier otro posible curso de acción política: cuando se produce un conflicto de criterios, se ha de estudiar con cuidado las medidas de discriminación inversa, que pueden ser lícitas y posibles según las circunstancias y las condiciones, pero no obligatorias sin más cualificación.

Asimismo, la discriminación inversa, aun siendo justa, puede suscitar efectos sociales negativos que sería necio desconsiderar con el kantiano fiat iustitia et ruat caelum: las reacciones de agravio comparativo, la posible reestigmatización social de las personas inversamente discriminadas («entró por la cuota, pero no vale nada») y otras objeciones semejantes, que no deben aceptarse acríticamente sino que han de contrastarse sociológicamente, pueden constituir serios obstáculos de hecho a la extensión de las medidas de discriminación inversa, que han de valorarse políticamente.

En síntesis, se debe reconocer que la discriminación inversa es un tipo de medida que tiene sus límites. En general, como en todo, la sensatez ha de operar a la hora de diseñar cualquier política de acción positiva, incluidas de manera muy particular las de discriminación inversa (pero conste que hago esta advertencia más bien para aviso de desconfiados, pues las políticas españolas y, en general, europeas son muy morigeradas en comparación con las del otro lado del Atlántico y se hallan todavía lejos de sobrepasar los límites razonables). Y, en especial, la temporalidad de las medidas de discriminación inversa es un rasgo que nadie, entre quienes las han propugnado, ha olvidado mencionar: nada en la discriminación inversa propugna el dar la vuelta a la tortilla porque deban ser otros, u otras, quienes tengan la sartén por el mango, sino que la consecución de los objetivos llama a desactivar su aplicación. Y téngase en cuenta que la misma definición de los objetivos ha de hacerse políticamente, sin que sea forzoso siempre perseguir los objetivos más maximalistas: según las circunstancias, puede ser más sensato plantearse no tanto el logro de la igualdad plena e ideal cuanto apuntar a ella tras la utilización de las cuotas como forma de denuncia y visualización de las desigualdades presentes.

\section{La fundamentación de la sentencia del caso Kalanke}

La sentencia del TJCE de 17 de octubre de 1995 está sorprendentemente poco y mal argumentada para las pautas habituales del Tribunal y la importancia del tema ${ }^{6}$. Sin duda, muchas de sus escuetas referencias remiten a

${ }^{6}$ De la misma opinión es Ballestrero, «Goals are good...» cit., p. 257.

Sobre esta sentencia, en parte con una argumentación sustancialmente coincidente con la aquí mantenida y en parte con comentarios jurídicos diferentes, relativos al Derecho internacional, el comunitario y el constitucional español, véase Teresa Pérez del Río, «La acción positiva. Justificación jurídico-constitucional», Jóvenas, nn. 4-5, 1995, pp. 82-91. 
la argumentación del Abogado General, Giuseppe Tesauro, que aunque es mucho más amplia -y, a decir verdad, algo desordenada, y hasta farragosa-, no por ello resulta más convincente. Voy a ordenar la exposición que sigue en torno al criterio general contenido en la sentencia y a las tres razones que intentan desarrollarlo. Al hilo de esos puntos, y siempre que sea pertinente, tomaré también en consideración los argumentos del Abogado General.

\section{El reproche de trato discriminatorio}

El criterio general de la sentencia es la afirmación del número 16 de que la norma impugnada «entraña una discriminación por razón de sexo» prohibida por la Directiva 76/207. Esta Directiva -esto es, una norma aprobada por el Consejo de la Comunidad que el Tratado obliga a los Estados miembros a incorporar a su legislación- en su art. 1.1

«contempla la aplicación [...] del principio de igualdad de trato entre hombres y mujeres en lo que se refiere al acceso al empleo, incluida la promoción, y a la formación profesional, así como a las condiciones de trabajo...»,

y en su art. 2.1 dice que tal principio

«supone la ausencia de toda discriminación por razón de sexo, bien sea directa o indirectamente, en lo que se refiere, en particular, al estado matrimonial o familiar».

Ahora bien, la afirmación de la sentencia de que la norma del Land de Bremen «entraña una discriminación» o bien está recogiendo sólo el significado descriptivo del término «discriminación», entendiéndolo como mera distinción, que podría estar justificada, o bien está afirmando apodícticamente, sin aportar una sola razón en favor de tal conclusión, que la preferencia de la normativa de Bremen es contraria al Derecho comunitario.

Aparentemente, la discusión de los números siguientes de la sentencia sugeriría que el Tribunal, como había hecho en alguna ocasión anterior, acepta la posibilidad de una discriminación en el primer sentido, como cuando recuerda su aceptación precedente de la posibilidad de distinciones de trato «discriminatorias en apariencia» (n. 18). Y así, mientras por un lado el n. 16 de la sentencia afirma sin más que la norma nacional impugnada «entraña una discriminación por razón de sexo», por otro lado, a renglón seguido, en el n. 17, precisa:

«No obstante, se debe examinar si tal norma nacional puede ampararse en el apartado 4 del artículo 2, conforme al cual la Directiva «no obstará a las medidas encaminadas a promover la igualdad de oportunidades entre hombres y mujeres, en particular para corregir las desigualdades de hecho que afecten a las oportunidades de las mujeres».

Sin embargo, las razones que pretenden justificar la inaplicabilidad al caso de este último precepto ponen de manifiesto que en realidad el TJCE termina entendiendo el principio de no discriminación en su sentido peyorativo, 
como distinción injusta, acogiendo así el significado en el que usa siempre el término el Abogado General en sus conclusiones. De este modo, la sentencia incorpora por vía implícita el, en mi opinión, injustificado prejuicio contra las distinciones o diferencias de trato en favor de las mujeres que trasluce la argumentación del Abogado General, una argumentación particularmente formalista en su abstracción a propósito de las desigualdades reales y de las circunstancias capaces de influir de manera efectiva en ellas. Veámoslo considerando en mayor detalle las tres razones aducidas por el Tribunal.

\section{Sobre la interpretación restrictiva: excepciones y cualificaciones}

La primera razón es que, según la sentencia, el citado art. 2.4 de la Directiva constituye «una excepción» a un derecho individual que, como tal excepción, debe interpretarse restrictivamente (n. 21). Sin embargo, el Tribunal confunde aquí claramente excepción y cualificación. Por ejemplificar esta distinción con la clásica prohibición de entrada de perros en un local, una cosa es la excepción que taxativamente dice: «No obstante, se autoriza la entrada de perros lazarillos» y otra bien distinta la cualificación que dice: «La prohibición anterior no se refiere a la entrada de perros por causas razonablemente justificadas». Mientras en el primer caso, ante el supuesto de la entrada de un perro antidroga o bien la excepción mantiene la prohibición o bien debe suplementarse mediante la creación por analogía de una nueva excepción que autoriza aquella entrada, en cambio, en el segundo caso la cualificación, que configura directamente el alcance y sentido de la prohibición, lleva a interpretar de forma natural como razonable la entrada de perros antidroga. Pues bien, si se lee el texto de la Directiva, ya citado, la exigencia de promover la igualdad de oportunidades para corregir desigualdades de hecho no parece que excepcione en el anterior significado, sino que cualifica o sirve para interpretar el sentido apropiado de la exclusión de discriminaciones injustas, que no ha de interpretarse restrictivamente, sino correctamente.

\section{¿Una preferencia absoluta?}

La segunda razón mencionada en la sentencia para considerar discriminatoria, en el sentido de injustificada, la norma del Estado de Bremen es que

\footnotetext{
«una normativa nacional que garantiza la preferencia absoluta e incondicional de las mujeres en un nombramiento o promoción va más allá de una medida de fomento de la igualdad de trato» (n. 22; la cursiva es mía).
}

Esta parece ser, a fin de cuentas, la línea de resistencia básica de la sentencia, que parece querer excluir cualquier forma de reserva de cuotas como mecanismo de igualación de las oportunidades. Sin embargo, el carácter 
absoluto e incondicional de la preferencia de la ley de Bremen es afirmado sin más pero no justificado. Más todavía, es afirmado contra toda evidencia, pues es indiscutible que una preferencia por las mujeres sometida a dos condiciones graves, como son la igualdad de capacitación y la existencia de infrarrepresentación en el sector laboral correspondiente, no es incondicional o absoluta ${ }^{7}$.

Hasta el punto de que, en realidad, en casos como éstos no hay una cuota en el sentido fuerte de la expresión, como reserva de un puesto con independencia de la mejor cualificación, sino, todo lo más, lo equivalente al otorgamiento de un punto extra para la mujer que, en igualdad de condiciones, opta por una plaza en un sector en el que hay infrarrepresentación. La conclusión es tanto más sorprendente cuanto que en las conclusiones del Abogado General se razonaba que en este caso

«no se trata de cuotas rígidas (que fijan un cierto porcentaje de puestos a obtener con independencia del mérito de las personas afectadas por las medidas), ni de cuotas que fijen exigencias mínimas que se deban cumplir. Se trata, por el contrario, de cuotas que no instauran un trato preferente en favor de las mujeres más que en presencia de una cualificación equivalente a la de los concurrentes de sexo masculino» (n. 10).

\section{Igualdad de oportunidades y de resultados: individuos y grupos}

La tercera razón de la sentencia, en fin, es la distinción entre medidas para la promoción de la igualdad de oportunidades y medidas de aplicación de tal igualdad. El texto literal de la sentencia en este punto es el siguiente:

\footnotetext{
«Además, procede añadir que un sistema de dicha naturaleza, en la medida en que pretende establecer una igualdad de representación de la mujer en relación con el hombre en todos los grados y niveles de un servicio sustituye la promoción de la igualdad de oportunidades contemplada en el apartado 4 del artículo 2 por su resultado, que sólo podría alcanzarse a través de la aplicación de dicha igualdad de oportunidades» (n. 23; cursiva mía).
}

Literalmente entendida, parece una distinción que no diferencia -típica del más rancio, y con razón denostado, formalismo jurídico-, según la cual los poderes públicos podrían alentar a que la sociedad confiera iguales oportunidades a hombres y a mujeres pero sin poder emprender medidas para garantizar de manera efectiva tal forma de igualdad entre ambos, como si lo primero fuera posible o útil sin lo segundo. Sin embargo, lo más probable es que, de forma oscura, el Tribunal esté asumiendo así el reductivo concepto de la igualdad de oportunidades que constituye el núcleo de la argumentación del Abogado General.

${ }^{7}$ Esta crítica, contenida ya en la primera versión de este escrito, aparece también en Ballestrero, «Goals are good...» cit., p. 259. 
En efecto, el Abogado General, interpretando la referencia del citado art. 2.4 a «la igualdad de oportunidades entre hombres y mujeres» en el sentido más restrictivo posible, coincidente con el punto de vista meritocrático del liberalismo tradicional, la reduce prácticamente a la exclusión individualizada de cualquier obstáculo a la inscripción o acceso a una carrera que es necesariamente desigual en los resultados. En este entendimiento individualista la igualdad de oportunidades viene a coincidir con la simple igualdad formal ante la ley, que permite por igual a los pobres y los ricos dormir bajo los puentes y vivir en un palacio, esto es, en el caso concreto, que excluye sin análisis ni matización alguna la utilización de criterios como la raza, el sexo, el nacimiento, la religión o similares.

Conforme al esquema anterior, el Abogado General bien puede insistir repetidamente en que la igualdad de oportunidades no equivale a la igualdad de resultados (cf. nn. 13, 19, 22 y 25), puesto que, individualmente considerada, la igualdad de oportunidades es siempre una igualdad en la partida para establecer desigualdades en la meta. Sin embargo, es bien dudoso que la Directiva adopte ese punto de vista cuando -si se me permite repetir el texto del art. 24- se toma la preocupación de autorizar

«las medidas encaminadas a promover la igualdad de oportunidades entre hombres y mujeres, en particular para corregir las desigualdades de hecho que afecten a las oportunidades de las mujeres»".

Si el problema de la desigualdad de las mujeres no es sólo individual sino que, como reconoce el Abogado General, «concierne a todas las mujeres en cuanto tales» (n. 18), no es difícil ver cómo la previsión de una medida que, como las cuotas, facilita individualmente a algunas mujeres la obtención de ciertos resultados es una clara forma o instrumento para aumentar las iguales oportunidades de las mujeres conjuntamente consideradas. Pero esto hay que verlo más despacio.

No es descabellado pensar que la llamativa desigualdad de hecho que en puestos y actividades de prestigio afecta a la igualdad de oportunidades de las mujeres puede ir siendo corregida mediante la especial facilitación de su ocupación y desempeño por ellas, de forma que sirvan de modelos de rol positivos para otras mujeres y para el conjunto de la sociedad ${ }^{8}$. Hasta ahora, hay que reconocer que la utilización de los mecanismos tradicionales, asociados sobre todo a la exclusión de obstáculos propia de la simple igualdad formal, se ha mostrado bien mostrenca a la hora de facilitar el acceso de mujeres a las funciones sociales más valoradas y prestigiosas. Para comprobarlo

${ }^{8}$ Este es, con poco margen para la duda, el sentido de la citada Recomendación del Consejo de 13 de diciembre de 1984 que, aunque como tal no es vinculante, el propio Abogado General reconoce, conforme a la doctrina del propio TJCE, como ayuda para la interpretación del Derecho comunitario y como complemento de éste (cf. el n. 20 de las Conclusiones del Abogado General, así como la Sentencia del TJCE de 13 diciembre de 1989, Grimaldi, C 322/1988, nn. 18-19). Así, el número 1 de dicha disposición recomienda a los Estados miembros «Que adopten una política de acción positiva destinada a eliminar las desigualdades de hecho, de las que son objeto las mujeres en la vida profesional, así como promover los empleos mixtos desarrollando unas medidas generales específicas apropiadas [...] a fin de: (a) eliminar o compensar los efectos perjudiciales que, para las mujeres que trabajan o que buscan un empleo, provienen de actitudes, comportamientos y estructuras basadas en la idea de un reparto tradicional de las funciones entre los hombres y las mujeres en la sociedad; (b) estimular la participación de las mujeres en las diferentes actividades de los sectores de la vida profesional en los que actualmente tienen una baja representación, en particular en los sectores de futuro y a niveles superiores de responsabilidad, para conseguir una mejor utilización de todos los recursos humanos». 
no hace falta más que echar una ojeada a las cúpulas financieras, empresariales, administrativas, judiciales y políticas en los países occidentales (del resto no hablamos). El Abogado General, además de su oposición jurídica por discriminatorias, considera sin embargo que «es más que evidente» que las cuotas tampoco sirven para conseguir la igualdad real (cf. n. 18) y como lo evidente excusa de cualquier demostración, no acompaña esta afirmación empírica de ningún dato ni argumento sociológico. En realidad, que las cuotas sean un medio inadecuado para obtener el fin de la igualdad está lejos de ser evidente, y aunque tampoco sea indiscutible su adecuación universal y perfecta ${ }^{9}$, tanto el sentido común como la defensa que de ellas se hace desde una buena parte del pensamiento feminista sugieren que no deben de ser tan inapropiadas para ir avanzando en una más efectiva igualdad de oportunidades para las mujeres.

En todo caso, la línea de resistencia fundamental del Abogado General está en el mencionado argumento jurídico de que la igualdad de oportunidades es incompatible con la igualdad de resultados, esto es, con la atribución directa de iguales puestos a hombres y a mujeres, como muy modesta y limitadamente, en efecto, pretendía la política de cuotas en la función pública del Estado de Bremen. Sin embargo, esa contraposición entre igualdad de oportunidades y de resultados, que es innegable ${ }^{10}$, opera únicamente cuando se adopta la perspectiva del individuo, pero no la del grupo (entendido éste simplemente como conjunto de individuos). Así, es cierto que cuando a un individuo se le da una igual oportunidad que a otros sobre algo (p. ej., la educación o el acceso a un cargo público), lo que se le da es una posibilidad y no el bien o resultado en cuestión, mientras que cuando se iguala en resultados a dos individuos con diferentes méritos necesariamente se han debido desigualar sus oportunidades.

Ahora bien, en cuanto entra en juego la variable del grupo, la preferencia en ciertos resultados hacia algunos individuos que forman parte del grupo tradicionalmente discriminado sobre individuos del grupo tradicionalmente privilegiado puede cumplir dos funciones: por un lado, incrementar

${ }^{9}$ Cf. mi artículo «Discriminación inversa e igualdad» cit., pp. 84-6.

${ }^{10}$ Cf. el claro análisis de Giovanni Sartori, Elementi di teoria politica, Bolonia, Il Mulino, 1987; cito por la t. c. de María Luz Morán, Elementos de teoría política, Madrid, Alianza, 1992, pp. 90-92 y 95-7. 
la igualdad de resultados globales entre los dos grupos, que, por hipótesis, son desiguales en tal aspecto como efecto de la discriminación tradicional; $y$, por otro lado, realizar una más apropiada igualdad en las oportunidades del conjunto de las personas pertenecientes al grupo tradicionalmente discriminado, al alentarlas a dotarse de la formación y las condiciones necesarias y a no desistir de intentar ocupar lugares considerados inaccesibles o de muy difícil acceso $^{11}$. Esta perspectiva del grupo puede ser muy bien la adoptada por la Directiva de la CEE. En realidad, el propio Abogado General la suscribe en algún momento, aunque luego la abandone en la sustancia de su argumentación, cuando relaciona estrechamente la igualdad de posibilidades y la igualdad sustancial (n. 9) y llega a reconocer que las desigualdades de hecho que afectan a las personas por su pertenencia a determinados grupos deben ser atacadas mediante «un derecho desigual» como «instrumento de realización de la igualdad» ${ }^{12}$. Si este reconocimiento no es mera retórica, significa que la igualdad de oportunidades entre los grupos puede ser realizada mediante medidas de desigualdad entre los individuos, como la que se impuso por el Estado de Bremen en el caso Kalanke.

Claro que esto supone reconocer que, como antes avancé, las políticas de discriminación inversa no son políticas de igualdad sustancial absoluta,

11 El economista americano Lester Thurow ha utilizado expresivamente la clásica imagen de la carrera, típico reflejo de la igualdad de oportunidades, para ilustrar este proceso: «Supongamos que se ha identificado a un grupo que sufre negación de iguales oportunidades. ¿Cómo debe corregirse esta situación? Imaginemos una carrera en la que a algunos corredores se les ha asignado una pesada carga porque pertenecen a un determinado grupo. A causa de este handicap el corredor medio con carga quedará rezagado del corredor medio sin carga, aunque algunos corredores con carga adelantarán a algunos corredores sin carga. Ahora supongamos que alguien agita una varita mágica y que las cargas desaparecen de las espaldas de todos los corredores. Si los dos grupos de corredores son iguales en capacidad, la principal diferencia entre los grupos con carga y sin carga deja de aumentar, pero aquellos que sufrían por la discriminación previa nunca se equipararán. Si se tratara de una carrera donde los padres en cabeza pudieran pasar el relevo a sus hijos, no habría igualación de la carrera ni siquiera a través de generaciones. La carrera sólo podría volverse limpia si cada uno fuera obligado a parar y a comenzar de nuevo en la misma línea de salida, si todos los que no llevaban carga fueran obligados a cargar peso hasta que las diferencias en el promedio de ejecución de grupos desaparecieran o si quienes habían sufrido desventajas en el pasado recibieran privilegios especiales hasta que se equiparasen» («A Theory of Groups and Economic Redistribution», Philosophy and Public Affairs, vol. 9, n. 1, 1979, p. 35).

12 Dice textualmente el Abogado General que «el principio de igualdad sustancial implica tomar en consideración las disparidades de hecho ligadas a la pertenencia a una categoría de personas o a un grupo social determinado, permitiendo e imponiendo eliminar, o al menos neutralizar, mediante medidas específicas, los efectos desiguales y perjudiciales que resultan de esas disparidades para las personas que pertenecen al grupo en cuestión», de modo que, según él, sería posible «legitimar un derecho desigual [...como] instrumento de realización de la igualdad. En definitiva, el principio de igualdad sustancial completa el principio de igualdad formal, al que no permite añadir más que las derogaciones que están justificadas por el fin al que éstas tienden: asegurar una igualdad efectiva» (n. 16). 
que pretendan afectar al conjunto de las jerarquías sociales en la distribución de bienes, sino, precisamente, políticas de igualdad de oportunidades entre grupos desiguales de hecho. Si se quiere visualizar esquemáticamente, la desigualdad de hecho entre hombres y mujeres en la distribución de puestos de prestigio puede representarse con una pirámide que, simplificadamente, coloca a los hombres arriba y a las mujeres abajo. Pues bien, ideal y también simplificadamente, una política de discriminación inversa sistemática y masiva conduciría a la misma pirámide pero dividida por la mitad a izquierda y derecha entre hombres y mujeres. La pirámide sigue estableciendo las mismas desigualdades de resultados entre los distintos individuos, pero -salvo que se afirme que las mujeres son en promedio inferiores a los hombreses al fin el producto y el incentivo de una igual distribución de las oportunidades entre el grupo de los hombres y el de las mujeres para el acceso a los puestos socialmente más valorados ${ }^{13}$.

\section{Conclusión: igualdades y discriminaciones}

Quizá la anterior conclusión parezca pobre y hasta poco atractiva para quienes desean una mayor igualdad social no sólo con independencia del sexo, sino en el sentido económico, cultural y político. Sin embargo, es aquel ideal y no éste el que se persigue cuando se habla de igualdad de oportunidades

${ }^{13}$ En este sentido, las políticas de discriminación inversa no garantizan -porque no es su pretensión hacerlola igualdad de oportunidades en el interior del grupo de las mujeres, aunque tampoco la excluyen. Por esa razón no me parece acertada la segunda de las tres condiciones sustantivas que Manuel Atienza exige para justificar la discriminación inversa: «tendría que darse el caso de que esa medida afectara positivamente, al menos en forma indirecta, a un grupo extenso de mujeres y que no redundara básicamente en beneficio de las mejor situadas socialmente» («Un comentario al caso Kalanke» cit., p. 10). A mi modo de ver, en cambio, las políticas de discriminación inversa, que de manera casi inevitable redundarán en beneficio de las mujeres socialmente mejor situadas, no por ello dejarán de beneficiar a las mujeres en su conjunto, siquiera sea indirectamente, disminuyendo $\mathrm{y}$, en el límite, eliminando la imagen social minusvaloradora con las que tradicionalmente se las viene caracterizando por su pertenencia indiferenciada a un grupo.

Las otras dos condiciones sustantivas que Atienza propone para justificar la discriminación inversa, son que la medida sea «razonablemente eficaz y eficiente», y que no haya «ninguna otra medida alternativa [...] que afecte en menor grado a derechos fundamentales de los individuos». Considero a la primera perfectamente razonable -valga la redundancia-, pero tengo reservas sobre la otra. Por un lado, no es claro que la discriminación inversa implique sacrificar derechos fundamentales, pues, en el plano de la justificación moral al menos, es debatible si hay o no un derecho a ser elegido sólo por los méritos, sin posibilidad de introducir ninguna otra consideración, que, por cierto, aparece como necesaria ante la igualdad de méritos (reconozco, no obstante, que en el plano jurídico al menos, preceptos como los artículos 23.2 y 103.3 de nuestra Constitución pueden suscitar objeciones en este punto, por más que alguna base para matizar una absolutización del criterio de los méritos exista en alguna sentencia del Tribunal Constitucional, como la 27/1991, de 14 de febrero). Por otro lado, si Atienza acepta que la discriminación inversa puede justificarse aunque afecte a derechos fundamentales, siquiera sea «en menor grado», es que ella misma o, preferiblemente, sus objetivos de igualdad deben tener el rango o valor de derecho fundamental, lo que animaría a excluir la absolutización del criterio de los méritos. 
entre hombres y mujeres. Debe reconocerse que no se trata de un ideal completo o suficiente, sino sólo de una exigencia necesaria, diría que incluso mínima si no fuera por lo lejos que todavía nos encontramos de ella. Es, en realidad, la elemental aspiración a eliminar una forma vieja, persistente e injusta de discriminación que las estructuras sociales insisten en mantener por encima de las propuestas y buenos deseos de las leyes. Pero, como lo muestra la sentencia Kalanke, constituye una aspiración difícil de lograr.

Para concluir, quién sabe si los magistrados y el Abogado General del Tribunal de Luxemburgo, como quizá tanta gente que opina en este debate, se han dejado también cautivar por la magia negativa de la palabra «discriminación», incluso si es inversa o positiva. Pero, por insistir en el núcleo duro de lo que he pretendido decir, en el fondo, que puede haber distinciones justificadas aunque tomen rasgos sospechosos como criterio es algo en realidad muy viejo. Tan viejo como la idea de que se deben tratar igualmente las situaciones iguales y desigualmente las que son desiguales. Una idea que, por más que formulada por vez primera por el esclavista, misógino y conservador Aristóteles, sigue sirviendo para quienes, a diferencia de él, creemos que tratar desigualmente a los injustamente desiguales puede ser un buen instrumento para ir logrando su igualdad. 